\title{
Adölesan idiopatik skolyozlu hastalarda Boston tipi korse kullanımının yaşam kalitesine etkisi
}

\section{The effect of Boston type corset on quality of life in adolescent idiopathic scoliosis}

\author{
Aliekber YAPAR' 1 , Alpaslan ŞENKÖYLÜ2'
}

${ }^{1}$ Sağlık Bilimleri Üniversitesi, Dr.Abdurrahman Yurtaslan Ankara Onkoloji Eğitim ve Araştırma Hastanesi, Ortopedi ve Travmatoloji Kliniği, Ankara/TÜRKiYE

${ }^{2}$ Gazi Üniversitesi Tıp Fakültesi, Ortopedi ve Travmatoloji Anabilim Dalı, Ankara/TÜRKiYE

\section{Öz}

Amaç: Adölesan İdiopatik Skolyoz (AiS) nedeniyle konservatif tedavi uygulanan hastalarda, korse (Boston tipi) kullanımının yaşam kalitesine etkisini Skolyoz Araştırma Cemiyeti'nin Sağlık ilişkili Yaşam Kalitesi-22 (Scoliosis Research Society- 22; SRS-22) anketi ile değerlendirmek

Gereç ve Yöntemler: Araştırma kesitsel tipte bir çalışmadır. Gazi Üniversitesi Tıp Fakültesi Hastanesi Ortopedi ve Travmatoloji Kliniğinde 2008 - 2017 yılları arasında tanı almış ve en az bir yıldır Ais tanısıyla takip edilen, konservatif tedavi uygulanan, yaş ortalaması 16,0 2,9 (min:11,00; maks:26) olan 22'si erkek (\%32,4), 46'sı kadın 68 hasta çalışmaya dâhil edilmiştir. Hastaların yaşam kalitesini değerlendirmek için SRS-22 anketi kullanıımıştır.

Bulgular: Çalışmaya katılan hastaların 23'ü $(\% 33,8)$ korse ile 45'i ise korsesiz takip edilmiştir. Hastaların son kontroldeki Cobb açısı dereceleri korse ile takip edilen grupta istatistiksel olarak anlamlı yüksek bulunmuştur $(p<0,001)$. Korse ile takip edilen ve korsesiz takip edilen her iki grup arasında SRS-22 toplam skoru, ağrı, fonksiyon, ruh sağlığı ve tedaviden tatmin skorları açısından istatistiksel olarak anlamlı fark bulunmamıştır ( $p>0,05)$. SRS-22 görünüşs skorunun ise korse ile takip edilen grupta istatistiksel olarak anlamlı düzeyde daha düşük olduğu saptanmıştır $(p=0,019)$.

Sonuçlar: Bu çalışmada korseli hastaların yaşam kalitelerinin korsesiz takip edilenlerle benzer olduğu saptanmıştır. Korseli grubun Cobb açı değerlerinin diğer gruba göre daha yüksek olması nedeniyle SRS-22 görünüş skorunun korselilerde daha düşük olduğu saptanmıştır. Korseli hastaların ağrı, fonksiyon, ruh sağığı ve tedaviden tatmin ile ilişkili yaşam kalitelerinin benzer olduğu ve genel olarak yaşam kalitelerinin korseden etkilenmediği bulunmuştur.

Anahtar Kelimeler: Adölesan idiopatik skolyoz, Yaşam kalitesi, SRS-22 anketi

Sorumlu Yazar": Aliekber YAPAR, Sağlık Bilimleri Üniversitesi, Dr.Abdurrahman Yurtaslan Ankara Onkoloji Eğitim ve Araştırma Hastanesi, Ortopedi ve Travmatoloji Kliniği, Ankara/TÜRKiYE

E-posta: aliekberyapar@hotmail.com

ORCID: 0000-0003-2227-2173

Gönderim: 28.09 .2019 kabul : 14.11 .2019

Doi: $10.18663 /$ tjcl.626226 


\section{Abstract}

Aim: To evaluate the effect of the corset (Boston type) on quality of life in patients who underwent conservative treatment for adolescent idiopathic scoliosis (AIS) with Scoliosis Research Society-22 (SRS-22) questionnaire.

Material and Methods: This is a cross-sectional study. Patients who were diagnosed with AIS between 2008 and 2017 in the Orthopedics and Traumatology Clinic of Gazi University Faculty of Medicine Hospital, treated conservatively and followed for at least one year were included in the study. Therewere 68 patients; 22 male (32.4\%) and 46 female. The mean age was $16.0 \pm 2.9$ ( $\min : 11.00 ; \max : 26$ ). SRS-22 questionnaire was used to evaluate health-related quality of life in patients.

Results: Twenty-three (33.8\%) of the patients were followed by corset and 45 of the patients were followed without the corset. Cobb angle degrees at the last follow-up were significantly higher in the corset group $(p<0.001)$. There was no statistically significant difference between SRS-22 total score, pain, function, mental health and satisfaction with management scores between the two groups followed by the corset and without corset ( $p>0.05$ ). SRS-22 self-image score was found to be significantly lower in the corset group $(p=0.019)$.

Conclusion: In this study, the quality of life of the patients with corsets was found to be similar to patients without corsets. Because of the Cobb angle values of the corset group were higher than the other group, the SRS-22 self- image score was found to be lower in the corsets. It was found that the quality of life associated with pain, function, mental health, and satisfaction with management was similar in patients with corsets and overall quality of life was not affected by the corset.

Key Words: Adolescent idiopathic scoliosis, Quality of life, Scoliosis Research Society - 22

\section{Giriş}

Skolyoz omurganın en sık görülen, üç boyutlu deformitesidir. Omurganın koronal planda radyolojik olarak tespit edilen $10^{\circ}$ ve üzeri eğriliği olarak tanımlanır [1].En sık görülen form idiopatik skolyozdur (\% 70-80). İdiopatik skolyoz nedeni tam olarak bilinmemektedir ve yaş gruplarına göre infantil (0-3 yaş),jüvenil (3-10 yaş) adölesan (10-18 yaş),erişkin (18 yaş ve üst) olmak üzere sınıflandırılır. Adölesan idiopatik skolyoz (AiS), sağlıklı pubertal çağ çocuklarda görülür ve en sık saptanan idiopatik skolyoz formudur ve sağlıklı çocukların ortalama \%2-4'ünde görülür [2].

Skolyoz tedavisinde ana amaç, erken tanı ile omurga deformitesini düzeltmek, eğriliğin ilerlemesini önlemek, ağrıyı azaltmak ve hastanın yaşam kalitesini iyileştirmektir. Skolyoz tedavisi planlaması; bireyin yaşına, cinsiyetine, matürasyonuna, eğriliğin derecesine, yönüne, tipine ve skolyozun ilerleme riskine göre belirlenir.Ais progresyonunun önlenmesi için tedavi seçenekleri egzersiz, korse tedavisi ve ameliyattır [3]. Tedavi görmeyen skolyoz hastalarında yaşam kalitesinde azalma, sakatlık, ağrı, artmış kozmetik deformite, fonksiyonel kısıtlamalar, nörolojik defisitler,kardiyo-pulmoner problemler ve yetişkinlik döneminde olası progresyon görülebilir.

Korse tedavisi, Ais hastalarında ameliyat dışı tedavi için yaygın olarak kullanılmaktadır ve etkili olduğu kanıtlanmıştır [1]. En sık torakolumbosakral ortez (TLSO) kullanılır. Deformitenin ilerlemesini kontrol etmek için stratejik bölgelerden baskı uygulayarak omurgayı stabilize eder [4]. Boston breysi, en yaygın kullanılan TLSO türüdür.Tedavi, eğriliğin progresif olarak tanımlandığı veya $20^{\circ}$ üzerindekabul edilen Cobb açısı eşik değerini aştığı (genellikle $25^{\circ}$ ile $30^{\circ}$ arasında) hastalarda başlar[5].Günde 18-22 saat boyunca takılan geleneksel TLSO, eğriliğin progresyonunu önlemede ve dolayısıyla ameliyattan kaçınma açısından korsesiz takibe göre üstündür[6]. Öte yandan; uyum, hareket ve kozmetik olarak potansiyel dezavantajları tartışılmaktadır. Korse tedavisine rağmen $45^{\circ} \mathrm{yi}$ geçen eğriliklerde cerrahi tedavi önerilir[3].

Görünüş ile ilgili kaygılar,Ais hastaları için sağılıkla ilişkili yaşam kalitesini değerlendirmede en önemli özelliklerden biridir[7]. AiS'e özgü yaşam kalitesini ölçen anketlerin ortaya çıkmasıyla, AiS hastalarının kendi omurga deformiteleri hakkındaki kişisel izlenimlerini ve tedavinin sonuçları hakkındaki algılarını anlamak mümkün hale gelmiştir.Ais'li kişilerde yaşam kalitesini değerlendirmek için, skolyozlu hastalara özgü sorular içeren anketler geliştirilmiştir[8-11]. Ais hastalarında en sık kullanılan, yaşam kalitesi ölçeği Skolyoz Araştırma Cemiyeti'nin Sağlık ilişkili 
Yaşam Kalitesi-22 (Scoliosis Research Society- 22; SRS-22]anketidir. Bu çalışmada Ais nedeniyle konservatif tedavi uygulanan hastalarda, Boston tipi korse kullanımının yaşam kalitesine etkisini SRS-22 anketi ile değerlendirmeyi amaçladık.

\section{Gereç ve Yöntemler}

Gazi Üniversitesi Tıp Fakültesi Hastanesi Ortopedi ve Travmatoloji Kliniğinde 2008-2017 yılları arasında tanı almış ve en az bir yıldır Ais tanısıyla takip edilen, konservatif tedavi uygulanan, yaş ortalaması 16,0 22,9 (min:11,00; maks:26) olan 22'si erkek (\%32,4), 46'sı kadın 68 hasta çalışmaya dâhil

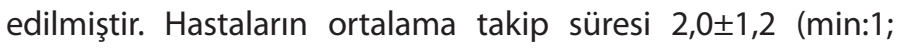
maks:8) yıldır. Bu çalışma kesitsel tipte bir çalışmadır. Konjenital omurga deformitesi olan bireyler, herhangi bir nöromusküler hastalığı olanlar, romatolojik rahatsızlığı olanlar, vücudunun herhangi bir yerinde tümörü olan, renal, kardiyovasküler, pulmoner sistem sorunu gibi kronik hastalığı olan ve Ais nedeniyle cerrahi tedavi uygulanmış bireyler çalışma dışında bırakılmıştır. Ayrıca korse kullanan hastaları çalışmaya dâhil etmeden önce tedavi için ön görülen sürelerde günlük korse kullanımına uyumları sorgulanmıştır. Hasta ve ailenin beyanına göre ön görülen sürelerin (18 saat) altında günlük korse kullanımı olan hastalar bu çalışmaya dâhil edilmemiştir. Korse tedavisi uygulanan hastalara, standart Boston tipi korse kullanılmıştır. Korseli ya da korsesiz takip edilen Ais hastalarında sağlıkla ilgili yaşam kalitesini değerlendirmek için SRS-22 anketi kullanılmıştır. SRS-22 anketi, skolyoza özgü bir yaşam kalitesi ölçeğidir. Skolyoz Araştırma Cemiyeti (Scoliosis Research Society) tarafından geliştirilmiş, birçok dilde geçerli ve güvenilir olduğu gösterilmiştir $[8,12,13]$. Türkçe versiyonunun geçerlilik ve güvenilirlik çalışması ise 2005 yılında Alanay ve arkadaşlarıtarafından yapılmıştır [12]. SRS-22 ağrı, genel görünüm/imaj, omurga fonksiyonu, ruh sağlığı ve tedaviden tatmin olmak üzere beş alt grup olmak üzere $5^{\prime}$ li likert tipinde toplam 22 sorudan oluşan bir ölçektir. Her bir soruda negatiften pozitife doğru değişen yanıtlar bulunur. En negatif cevap 1 ve en pozitif ise 5 puan alır. Her bir bölümden alınan puanlar toplanarak, cevap verilen soru sayısına bölünür. Böylece alt grupların skoru ve toplam sonuç skoru elde edilir. En düşük alınabilecek skor 1 en yüksek skor ise 5'tir. Ölçekten alınan skorum yüksek olması yaşam kalitesinin arttığını, düşük olması azaldığını gösterir. SRS-22 anket formu araştırmacı tarafından yüz yüze uygulanmıştır. Uygulama öncesi hasta ve ebeveynine bilgilendirilmiş onam formu okunarak imzalatılmıştır. SRS-22 skorları ile birlikte değerlendirilmek üzere hastaların en son kontrollerinde ölçülen Cobb açısı, Lenke tipi ve Risser evresi dosyaların retrospektif olarak taranması ile elde edilmiştir. Araştırma için Gazi Üniversitesi Etik Komisyonu'ndan onay alınmıştır. Bu araştırma Helsinki Deklarasyonu prensiplerine uygun olarak yapılmıştır. Tüm hasta ebeveynlerinden bilgilendirilmiş onarm formları alınmıştır.

\section{İstatistiksel Analiz}

Araştırma verilerinin istatistiksel analizleri için Statistical Package for Social Sciences (SPSS), Windows için sürüm 22.0 (SPSS Inc. Chicago, USA) bilgisayar paket programı kullanılmıştır. Tanımlayıcı istatistikler kısmında kategorik değişkenler sayı, yüzde verilerek, sürekli değişkenler ise ortalama \pm standart sapma ve ortanca (en küçük- en büyük değer) ile sunulmuştur. Sürekli değişkenlerin normal dağılıma uygunluğu görsel (histogram ve olasılık grafikleri) ve analitik yöntemler (Kolmogorov-Smirnov/Shapiro-Wilk testleri) kullanılarak değerlendirilmiştir. Yapılan normallik analizleri sonucu sürekli değişkenlere ait veriler normal dağılım gösteriyor ise iki grup arasındaki karşılaştırma analizleri için Independent Sample T test, normal dağılım sergilemiyorsa Mann-Whitney U testi kullanılmıştır. Bağımsız gruplar arasında kategorik değişkenler için yapılan karşılaştırma analizlerinde ki-kare testi kullanılmıştır. Bağımsız prediktörlerin ile SRS22 skorları arasındaki ilişki Sperman korelasyon analizi (normal dağılım göstermeyen değerler arasında) ve Pearson korelasyon analizi (normal dağılım gösteren değerler arasında) ile değerlendirilmiştir. Bu çalışmada istatistik anlamlılık düzeyi $\mathrm{p}<0,05$ olarak kabul edilmiştir.

\section{Bulgular}

Bu çalışmaya dâhil olan hastaların 45'i korsesiz 23'ü ise korseli takip edilmektedir. Her iki gruba ait demografik özelliklerin ve SRS-22 ölçek skorlarının değerlendirilmesi tablo 1'de sunulmuştur. Hastanın yaşı ve tanı yaşının korsesiz takip olan grupta istatistiksel olarak anlamlı daha yüksek olduğu saptanmıştır ( $p=0,016$ ve $p=0,007)$. Her iki tedavi grubun takip süreleri ise benzer bulunmuştur $(p=0,335)$. Korsesiz 
takip edilen grubun $\% 28,9^{\prime} u$ korseli takip edilen grubun ise \%39,1'i erkektir. Gruplar arasında cinsiyet dağılımları arasında anlamlı fark bulunmamıştır $(p=0,562)$. Korseli takip edilen

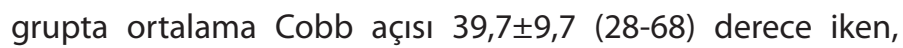
korsesiz grubun 25,0 99,3 (13-50) derece olduğu saptanmıştır ve gruplar arasındaki bu fark istatistiksel olarak anlamlı bulunmuştur $(p<0,001)$. SRS-22 ölçek toplam skor ve alt grup skorları tedavi grupları arasında karşılaştırıldığında görünüş alt grup skoru ortalamasının korseli grupta anlamlı düşük olduğu saptanmıştır $(p=0,019)$. Diğer alt grup skorlarının ve toplam skorun tedavi gruplarına göre yapılan karşılaştırmada istatistiksel olarak anlamlı farklı olmadığı bulunmuştur ( $p>0,05)$. Hastalara ait bazı tanımlayıcı özelliklerin SRS-22 ölçek skorları ile arasındaki ilişki tablo 2'de sunulmuştur. Hastaların yaşı, tanı anındaki yaşı, Risser evresi ve eğitim durumları ile SRS-22 ölçek skorları arasında anlamlı bir ilişki saptanmamıştır ( $p>0,05)$. Cobb açısı ile SRS-22 görünüş alt grubu arasında negatif yönlü orta derece istatistiksel olarak anlamlı bir ilişki saptanmıştır ( $r=-0,448 ; p<0,001)$ fakat Cobb açısı ile diğer skorlar arasında anlamlı bir ilişki bulunmamıştır ( $p>0,05)$.

\begin{tabular}{|c|c|c|c|}
\hline $\mathrm{N}=68$ & $\begin{array}{c}\text { Korsesiz Takip } n=45 \\
(\% 66,2)\end{array}$ & $\begin{array}{c}\text { Korseli Takip } n=23 \\
(\% 33,8)\end{array}$ & $p$ \\
\hline $\begin{array}{l}\text { Yaş, yıl } \\
\text { Ortalama } \pm \text { standart sapma } \\
\text { Ortanca (min-maks) }\end{array}$ & $\begin{array}{c}16,6 \pm 3,1 \\
16,0(12,0-26,00)\end{array}$ & $\begin{array}{c}14,7 \pm 2,2 \\
15,0(11,0-18,0)\end{array}$ & $0,016^{1}$ \\
\hline $\begin{array}{l}\text { Tanı Yaşı, yıl } \\
\text { Ortalama } \pm \text { standart sapma } \\
\text { Ortanca (min-maks) }\end{array}$ & $\begin{array}{c}14,57 \pm 2,8 \\
15,0(10-18,0)\end{array}$ & $\begin{array}{c}12,7 \pm 2,2 \\
12,8(10,0-16,0)\end{array}$ & $0,007^{1}$ \\
\hline $\begin{array}{l}\text { Cinsiyet, } \mathrm{n}(\%)^{*} \\
\text { Kadın } \\
\text { Erkek }\end{array}$ & $\begin{array}{l}32(71,1) \\
13(28,9)\end{array}$ & $\begin{array}{l}14(60,9) \\
9(39,1)\end{array}$ & $0,562^{2}$ \\
\hline $\begin{array}{l}\text { Takip süresi, yıl } \\
\text { Ortalama } \pm \text { standart sapma } \\
\text { Ortanca (min-maks) }\end{array}$ & $\begin{array}{c}2,0 \pm 1,3 \\
1,7(1,0-8,0)\end{array}$ & $\begin{array}{c}2,0 \pm 0,9 \\
1,8(1,0-4,0)\end{array}$ & $0,335^{1}$ \\
\hline $\begin{array}{l}\text { Cobb Açısı } \\
\text { Ortalama } \pm \text { standart sapma } \\
\text { Ortanca (min-maks) }\end{array}$ & $\begin{array}{c}25,0 \pm 9,3 \\
24,0(13,0-50,0)\end{array}$ & $\begin{array}{c}39,7 \pm 9,7 \\
38,0(28,0-68,0)\end{array}$ & $<0,001$ \\
\hline $\begin{array}{l}\text { SRS } 22 \text { Ağrı } \\
\text { Ortalama } \pm \text { standart sapma } \\
\text { Ortanca (min-maks) }\end{array}$ & $\begin{array}{c}3,9 \pm 0,7 \\
4,0(2,4-5,0)\end{array}$ & $\begin{array}{c}4,1 \pm 0,7 \\
4,2(2,4-5,0)\end{array}$ & $0,171^{3}$ \\
\hline $\begin{array}{l}\text { SRS } 22 \text { İmaj/Görünüş } \\
\text { Ortalama } \pm \text { standart sapma } \\
\text { Ortanca (min-maks) }\end{array}$ & $\begin{array}{c}3,3 \pm 0,8 \\
3,6(1,2-4,6)\end{array}$ & $\begin{array}{c}2,9 \pm 0,8 \\
3,0(1,2-4,4)\end{array}$ & $0,019^{3}$ \\
\hline $\begin{array}{l}\text { SRS } 22 \text { Fonksiyon } \\
\text { Ortalama } \pm \text { standart sapma } \\
\text { Ortanca (min-maks) }\end{array}$ & $\begin{array}{c}4,5 \pm 0,6 \\
4,6(2,8-5,0)\end{array}$ & $\begin{array}{c}4,3 \pm 0,8 \\
4,6(2,0-5,0)\end{array}$ & $0,545^{3}$ \\
\hline $\begin{array}{l}\text { SRS } 22 \text { Ruh Sağlığı } \\
\text { Ortalama } \pm \text { standart sapma } \\
\text { Ortanca (min-maks) }\end{array}$ & $\begin{array}{c}3,5 \pm 0,9 \\
3,6(1,6-5,0)\end{array}$ & $\begin{array}{c}3,6 \pm 0,7 \\
3,6(2,2-4,6)\end{array}$ & $0,927^{3}$ \\
\hline $\begin{array}{l}\text { SRS } 22 \text { Tedaviden Tatmin } \\
\text { Ortalama } \pm \text { standart sapma } \\
\text { Ortanca (min-maks) }\end{array}$ & $\begin{array}{c}3,6 \pm 0,8 \\
3,0(2,5-5,0)\end{array}$ & $\begin{array}{c}3,6 \pm 0,8 \\
3,5(2,0-5,0)\end{array}$ & $0,942^{3}$ \\
\hline $\begin{array}{l}\text { SRS } 22 \text { Toplam } \\
\text { Ortalama } \pm \text { standart sapma } \\
\text { Ortanca (min-maks) }\end{array}$ & $\begin{array}{c}3,8 \pm 0,6 \\
3,9(2,5-4,9)\end{array}$ & $\begin{array}{c}3,7 \pm 0,6 \\
3,9(2,3-4,4)\end{array}$ & $0,650^{3}$ \\
\hline $\begin{array}{l}{ }^{1} \text { Mann- Whitney U Testi } \\
{ }^{2} \text { Ki-Kare Testi } \\
{ }^{3} \text { Independent Student T-Testi }\end{array}$ & & & \\
\hline
\end{tabular}




\begin{tabular}{|c|c|c|c|c|c|}
\hline & $\begin{array}{c}\text { Tanı Yaşı } \\
\text { rs (p) }\end{array}$ & $\begin{array}{l}\text { Yaş } \\
\text { rs (p) }\end{array}$ & $\begin{array}{c}\text { Cobb Açısı } \\
\text { r(p) }\end{array}$ & $\begin{array}{c}\text { Risser Evresi } \\
\text { rs (p) }\end{array}$ & $\begin{array}{c}\text { Eğitim Durumu } \\
\text { rs (p) }\end{array}$ \\
\hline SRS-22 Ağrı & $-0,174(0,155)$ & $-0,197(0,108)$ & $0,028(0,818)$ & $-0,222(0,069)$ & $-0,060(0,628)$ \\
\hline SRS-22 İmaj/Görünüş & $0,236(0,052)$ & $0,196(0,109)$ & $-0,448(<0,001)$ & $0,134(0,276)$ & $0,203(0,097)$ \\
\hline SRS-22 Fonksiyon & $0,013(0,917)$ & $-0,020(0,871)$ & $-0,130(0,292)$ & $0,008(0,946)$ & $0,046(0,712)$ \\
\hline SRS-22 Ruh Sağlığı & $-0,109(0,375)$ & $-0,106(0,338)$ & $-0,060(0,628)$ & $-0,223(0,068)$ & $-0,077(0,535)$ \\
\hline SRS-22 Tedaviden Tatmin & $0,151(0,232)$ & $0,080(0,528)$ & $-0,085(0,507)$ & $0,030(0,813)$ & $0,036(0,777)$ \\
\hline SRS-22 Toplam & $-0,016(0,897)$ & $-0,084(0,569)$ & $-0,211(0,085)$ & $-0,158(0,199)$ & $0,015(0,905)$ \\
\hline rs: Spearman korelasyon kats & \multicolumn{5}{|c|}{ r: Pearson korelasyon katsayısı } \\
\hline
\end{tabular}

\section{Tartışma}

AiS nedeniyle ortaya çıkan görünüş deformitesinin ergenlerde sıklıkla yaşam kalitesini azalttığı, daha şiddetli skolyozlarda ise psikososyal sorunlara yol açabilecek etkilerinin olduğu gözlenmiştir [14, 15]. Hastaların takipte Cobb açıları kritik eşiği aşarsa büyüme sonunda erişkinlik döneminde engellilik, ağrı, artmış kozmetik deformite, fonksiyonel kısıtlamalar ve pulmoner problemler gibi ciddi sağlık sorunları riski de artar. Halen Ais konservatif tedavisinde korse kullanımı tartışmalıdır. Avrupa kıtasında birçok ülkede standart tedavi olarak kabul edilirken, Birleşik Krallık 'ta ve Amerika'da birçok merkezde standart tedavi olarak kabul edilmemektedir $[16,17]$. Korse kullanımının faydalarına ilişkin kanıt yetersizliğinden dolayı tedavideki yeri eleştirilmektedir [18, 19]. Etkili ve uyumlu korse kullanımı, hastalarda eğriliğin ilerleyici doğasını durdurmaya yardım ederek yaşam kalitesinin etkilenmesini de engeller. Etkili korse kullanımının önündeki en büyük engel günlük kullanım süresinin uzun olmasından kaynaklı hasta uyumu sorunudur. Korse kullanımının hastalığın seyrini yavaşlatarak skolyozun neden olduğu yaşam kalitesi düşüklüğü de engellediği açıktır. Bu çalışmada nerdeyse günün tamamına yakınını korseyle geçirmenin ya da korse kullanımının hastaların yaşam kalitesini ne kadar etkilediğini araştırmak amaçlanmıştır. Çalışmanın sonucunda korseli hastaların yaşam kalitelerinin korsesiz takip edilenlerle benzer olduğu saptanmıştır.Negrini ve arkadaşlarının yapmış olduğu sistematik derlemedeki tüm çalışmalar, korsenin eğriliğin ilerlemesini önlediğini göstermiştir ve düşük kanıt düzeyli sadece bir çalışmada da korse kullanılan ve korsesiz takip edilen hastalar arasında yaşam kalitesinin anlamlı farklılık göstermediği vurgulanmıştır [1, 20].
Çalışmamızda SRS-22 görünüş alt grup skorunun korselilerde daha düşük olduğu saptansa da ağrı, fonksiyon, ruh sağlığı ve tedaviden tatmin ile ilişkili yaşam kalitelerinin her iki grupta benzer olduğu ve SRS-22 ölçeği toplam skorunun da gruplar arasında farklı olmadığı bulunmuştur. Cobb açı değeri yüksek olan hastaların ilişkili bir şekilde görünüşleri ile ilgili yaşam kalitesi skorlarının düştüğü gözlenmiştir. Korseli grubun Cobb açı değerlerinin diğer gruba göre daha yüksek olması nedeniyle SRS-22 görünüş skorlarının korsesiz takip edilen hastalara göre daha düşük olması beklenen bir sonuçtur. Korse tedavisi tartışmalı olsa da Ais tedavisinin en etkili ve standart cerrahi dışı tedavi yöntemidir [1, 21-23]. Korse tedavisinde etkinliğini belirleyen en önemli faktörlerden biri ise hastaların öngörülen uygun sürede korse kullanmasıdır. Kullanım süresi için öngörülen rejimler, hastanın yaşına ve skolyozun ciddiyetine bağıı olarak günde 8 ila 24 saat arasında değişmektedir [24]. Kullanma süresi 16 saat ve üzerinde olan adölesanlarda eğrilik progresyonunu daha iyi kontrol edilmekte ve cerrahi tedavi ihtiyacı da belirgin olarak düşmektedir[20].Rahman ve arkadaşlarının korse kullanan hastaların uyumunu elektronik bir monitorizasyon tekniği ile incelemeyi amaçladığı gözlemsel bir çalışmada hastalara öngörülen korse kullanım süreleri ve uyum arasında bir ilişki olmadığı 55 hastanın sadece 8'inin $(\% 14,5)$ ön görülen sürelere \%100 uyumlu olarak korse kullandığı, \%65,5 hastanın (36 hasta) en az \%50 uyum sağladığı saptanmıştır [24]. Çalışmamızda hastaların korse kullanımı konusundaki uyumlarına hem hastanın hem de ailesinin ortak beyanlarına göre karar verilmiştir. Korseyi gerçekte aktif ve uygun süre (günde en az 16 saat) kullanan hastaların yaşam kalitelerinin korsesiz takip edilen hastalarla karşılaştırabilmek amaçlanmıştır. 
Çalışmamızda görünüş alt grup skoru ortalaması korsesiz takip edilen hastalarda $3,3 \pm 0,8$, korseli takip edilen grupta ise 2,9 $\pm 0,8$ bulunmuştur ve bu fark istatistiksel olarak anlamlı saptanmıştır. Carreon ve arkadaşlarının çalışmasında da her iki grup arasında görünüş alt grup skoru anlamlı farklı bulunmuştur ve korsesiz takip edilen grupta $4.28 \pm 0.58$ korseli takip edilen grupta 4.09 \pm 0.47 saptanmıştır [25]. Bizim çalışmamızda görünüş alt grup skorlarının her iki grupta da Carreon ve arkadaşlarınınçalışmasına göre daha düşük olduğu gözlenmiştir. Yine aynı çalışmada, çalışmamızla benzer şekilde SRS-22 görünüş skoru ile Cobb açısı arasında negatif bir ilişki olduğu $(r=-0.442 ; p<0,001)$ saptanmıştır [25]. Çalışmamızda yaş ve Risser evresinin yaşam kalitesi ile ilişkisi olmadığı saptanmıştır. Elde ettiğimiz sonuçlarla uyumlu olarak, Guo ve arkadaşları da her iki parametre ile yaşam kalitesi arasında ilişki olmadığını göstermiştir [26]. Çalışmamızda korseli ve korsesiz takip edilen her iki hasta grubunda yaş farkının anlamlı bulunmasına karşın, yaş ve hastalık ilişkili yaşam kalitesinin ilişkisiz bulunması gruplar arasındaki bu yaş farkının yaşam kalitesini etkilemediğini göstermektedir. Bu çalışmada her iki grupta da omurga fonksiyonu ile ilişkili yaşam kalitesinin ölçeğin diğer alt gruplarına göre daha yüksek skorlara sahip olması hastaların ciddi fonksiyonel kısıtılıklarının olmadığını göstermektedir. Ayrıca gruplar arasında fonksiyon alt grup skorlarının benzer olması korseli takip edilen grubun korse kullanmak durumdan kaynaklı bir fonksiyonel kısıtlılık yaşamadığı, aileleri ve arkadaşları ile normal aktivitelerini korsesiz takip edilen grup kadar yeterli gerçekleştirebildiklerini ve yaşam kalitelerinin etkilenmediğini göstermektedir.

\section{Sonuç}

$\mathrm{Bu}$ çalışmada korseli hastaların yaşam kalitelerinin korsesiz takip edilenlerle benzer olduğu tespit edilmiştir. Korseli grubun Cobb açı değerlerinin diğer gruba göre daha yüksek olması nedeniyle SRS-22 görünüş skorunun korselilerde daha düşük olduğu saptanmıştır. Korseli hastalarda ağrı, fonksiyon, ruh sağlığı ve tedaviden tatmin ile ilişkili yaşam kalitelerinin korsesiz takip edilenler ile benzer olduğu ve genel olarak yaşam kalitelerinin korseden etkilenmediği bulunmuştur. Her ne kadar ortopedist için korse tedavisi kararı almak zor olsa da tüm tartışmalara rağmen ilerleyici eğriliklerde cerrahi dışı tedavi seçenekleri arasında en sık tercih edilen konservatif tedavi şeklidir. Elde ettiğimiz verilerin, hem ortopedistler hem de aile ve hastalar için hala netleşmemiş bir konu olan korse kaynaklı yaşam kalitesi azalması konusundaki düşüncelere katkı sağlayacağı kanaatindeyiz. Literatürde de hala güncelliğini koruyan bu konuda daha büyük örnek grupları ile yapılacak randomize kontrollü klinik çalışmalara ihtiyaç vardır.

\section{Maddi destek ve çıkar ilişkisi:}

Çalışmayı maddi olarak destekleyen kişi/kuruluş yoktur ve yazarların herhangi bir çıkara dayalı ilişkisi yoktur.

\section{Kaynaklar}

1. Weinstein SL, Dolan LA, Wright JG, Dobbs MB. Effects of bracing in adolescents with idiopathic scoliosis. The New England journal of medicine 2013; 369: 1512-21.

2. El-Hawary R, Akbarnia BA. Early Onset Scoliosis - Time for Consensus. Spine deformity 2015; 3: 105-6.

3. Negrini S, Aulisa AG, Aulisa L et al. 2011 SOSORT guidelines: Orthopaedic and Rehabilitation treatment of idiopathic scoliosis during growth. Scoliosis 2012; 7: 3.

4. Labelle H, Dansereau J, Bellefleur C, Poitras B. Three-dimensional effect of the Boston brace on the thoracic spine and rib cage. Spine 1996; 21: 59-64.

5. Lonstein JE. Scoliosis: surgical versus nonsurgical treatment. Clinical orthopaedics and related research 2006; 443: 248-59.

6. Ohrt-Nissen S, Lastikka M, Andersen TB, Helenius I, Gehrchen M. Conservative treatment of main thoracic adolescent idiopathic scoliosis: Full-time or nighttime bracing? Journal of orthopaedic surgery (Hong Kong) 2019; 27: 2309499019860017.

7. Smith PL, Donaldson S, Hedden D et al. Parents' and patients' perceptions of postoperative appearance in adolescent idiopathic scoliosis. Spine 2006; 31: 2367-74.

8. Asher M, Min Lai S, Burton D, Manna B. The reliability and concurrent validity of the scoliosis research society-22 patient questionnaire for idiopathic scoliosis. Spine 2003; 28: 63-69.

9. Botens-Helmus C, Klein R, Stephan C. The reliability of the Bad Sobernheim Stress Questionnaire (BSSQbrace) in adolescents with scoliosis during brace treatment. Scoliosis 2006; 1: 22. 
10. Sanders JO, Harrast JJ, Kuklo TR, et al. The Spinal Appearance Questionnaire: results of reliability, validity, and responsiveness testing in patients with idiopathic scoliosis. Spine 2007; 32: 2719-22.

11. Vasiliadis E, Grivas TB, Gkoltsiou K. Development and preliminary validation of Brace Questionnaire (BrQ): a new instrument for measuring quality of life of brace treated scoliotics. Scoliosis $2006 ; 1: 7$

12. Alanay A, Cil A, Berk $H$, et al. Reliability and validity of adapted Turkish Version of Scoliosis Research Society-22 (SRS-22) questionnaire. Spine 2005; 30: 2464-68.

13. Asher M, Min Lai S, Burton D, Manna B. Discrimination validity of the scoliosis research society-22 patient questionnaire: relationship to idiopathic scoliosis curve pattern and curve size. Spine 2003; 28: 74-78.

14. Freidel K, Petermann F, Reichel D, Steiner A, Warschburger P, Weiss HR. Quality of life in women with idiopathic scoliosis. Spine 2002; 27: 87-91.

15. Freidel K, Reichel D, Steiner A, Warschburger $P$, Petermann $F$ Weiss HR. Idiopathic scoliosis and quality of life. Studies in health technology and informatics 2002; 88: 24-29.

16. Altaf F, Gibson A, Dannawi Z, Noordeen H. Adolescent idiopathic scoliosis. BMJ 2013; 346: 2508

17. Hresko MT. Clinical practice. Idiopathic scoliosis in adolescents. The New England journal of medicine 2013; 368: 834-41.

18. Dolan LA, Donnelly MJ, Spratt KF, Weinstein SL. Professional opinion concerning the effectiveness of bracing relative to observation in adolescent idiopathic scoliosis. Journal of pediatric orthopedics 2007; 27: 270-76.
19. Dolan LA, Weinstein SL. Surgical rates after observation and bracing for adolescent idiopathic scoliosis: an evidence-based review. Spine 2007; 32: 91-100.

20. Negrini S, Minozzi S, Bettany-Saltikov J et al. Braces for Idiopathic Scoliosis in Adolescents. Spine 2016; 41: 1813-25.

21. Goldberg CJ, Moore DP, Fogarty EE, Dowling FE. Adolescent idiopathic scoliosis: the effect of brace treatment on the incidence of surgery. Spine 2001; 26: 42-47.

22. Noonan KJ, Weinstein SL, Jacobson WC, Dolan LA. Use of the Milwaukee brace for progressive idiopathic scoliosis. The Journal of bone and joint surgery American volume 1996; 78: 557-67.

23. Weinstein SL, Dolan LA, Cheng JC, Danielsson A, Morcuende JA. Adolescent idiopathic scoliosis. Lancet. 2008; 371: 1527-37.

24. Rahman T, Sample W, Yorgova P et al. Electronic monitoring of orthopedic brace compliance. Journal of children's orthopaedics 2015; 9: 365-69.

25. Carreon LY, Sanders JO, Polly DW et al. Spinal appearance questionnaire: factor analysis, scoring, reliability, and validity testing. Spine 2011; 36: 1240-44.

26. Guo J, Lau AH, Chau J et al. A validation study on the traditional Chinese version of Spinal Appearance Questionnaire for adolescent idiopathic scoliosis. European spine journal : official publication of the European Spine Society, the European Spinal Deformity Society, and the European Section of the Cervical Spine Research Society 2016; 25: 3186-93. 